\title{
Marx y la ontología del ser sociala
}

\section{Marx and the social being ontology}

\author{
José Fernando Siqueira da Silva ${ }^{b}$
}

\begin{abstract}
Resumen
La ontología en Marx es impensable sin la aprehensión de su teoría social en su totalidad. Es decir, se refiere a un de determinado tipo de ser, el ser social (como plantea Lukács), históricamente constituido a partir de determinadas condiciones socio-históricas. La teoría social de Marx se basa en tres pilares indisociables: la teoría del valortrabajo, la dialéctica materialista y la perspectiva de la revolución del orden burgués (como referencia objetiva y posible). La ortodoxia marxiana, para Lukács, está únicamente en su método de análisis que sirve como referencia para reconstruir procesos objetivamente existentes a partir de determinadas condiciones históricas. Por eso que la razón humana no construye la realidad, pero la reconstruye mentalmente, lo que impone que las categorías no sean conceptos impuestos por teorías del conocimiento, pero "determinaciones de existencia” (Marx). La perspectiva marxiana refunda la relación entre razón y realidad, como praxis social, reafirmando la emancipación humana como posibilidad histórica lograda por medio de la crítica radical-material al capital, a su forma de producción y reproducción social (el capitalismo), a la propiedad privada y al trabajo extrañadoalienado. Reflexionar sobre la categoría revolución hoy es tarea insubstituible para los revolucionarios, incluso los latinoamericanos.
\end{abstract}

Palabras clave: teoría social, ontología del ser social, totalidad.

\begin{abstract}
Abstrac
The ontology in Marx is inconceivable without the apprehension of his social theory in its entirety. In other words, it refers to a particular kind of being, the social being (as suggested by György Lukács), historically established from certain socio-historical conditions. Marx's social theory is based on three inseparable pillars : theory of labor value, dialectical materialism and the prospect of the revolution of the bourgeois order (as objective and possible reference). The Marxist orthodoxy, for Lukács, is only in his method of analysis which serves as a reference to realign processes existing objectively from certain historical conditions. The Marxist perspective refonds the relationship between reason and reality as social practice, reassuring human emancipation as a historical possibility achieved through radical criticism to the capital, its
\end{abstract}

Kera Yvoty: reflexiones sobre la cuestión social. Vol. 1, 2016,

ISSN9.(impreso): 2519-7797

a Texto comunicado y publicado en forma de ponencia en el "I Congreso Latinoamericano de Teoría Social - ¿Por qué la Teoría

Social? Las posibilidades críticas de los abordajes clásicos, contemporáneos y emergentes", 19-21 de agosto de 2015, Buenos Aires, Universidad de Buenos Aires (UBA).

b Consejo Nacional de Desarrollo Científico y Tecnológico (CNPQ), Brasil.

Correspondencia a:

jfernandoss@terra.com.br

Cita:

Silva, J. F. S. (2016). Marx y la ontología del ser social. Kera Yvoty: reflexiones sobre la cuestión social, 1, 63-79.

Recibido:

31 agosto 2016

Aceptado:

20 noviembre 2016 
means of social production and reproduction (capitalism), its private property and alienated labor

Keywords: social theory, social being ontology, entirety.

[...] toda ciência seria supérflua se a forma de manifestação e a essência das coisas coincidissem imediatamente[...]. (Marx, 1985b, v. III/2, p. 271)

\section{Observaciones introductorias}

El texto que sigue tiene por objetivo principal explicitar y analizar algunos puntos fundamentales sobre la teoría social de Marx destacando las contribuciones ofrecidas por Lukács en sus estudios de madurez registrados, sobre todo, en dos obras maestras: "La ontología del ser social" (Lukács, 2012 y 2013) y Prolegómenos para una ontología del ser social” (Lukács, 2010). Además, es necesario destacar que esa delimitación no desconsidera el conjunto de la obra de Lukács, mucho menos promueve una ruptura entre las producciones de juventud y de madurez del autor. Menos aún debe ser aprehendida separadamente del conjunto de la producción marxiana (de Marx). El destaque dado a las obras aquí indicadas posee una justificación central: la innegable densidad de los análisis desarrollados por Lukács acerca de la ontología del ser social en esos estudios, lo que, en absoluto, significa descartar otras publicaciones no menos importantes y decisivas para los escritos de madurez ${ }^{1}$. Ese mismo procedimiento es válido para el conjunto monumental de la obra de Marx, absolutamente impensable sin la unidad-diversa entre los conocidos estudios de juventud hasta 1845 (algunos elaborados junto con Engels) ${ }^{2}$ y las

1 Me refiero, por ejemplo, a sus estudios sobre la estética (introductoriamente publicados en "Introdução a uma estética Marxista" (1978) y algunos importantes fragmentos de obras tales como "O marxismo ortodoxo" y "A decadencia ideológica" (Lukács, 1981).

2 El acierto de cuentas con el idealismo alemán y con el materialismo a-histórico y mecanicista (que tenía en Feuerbach su versión más desarrollada), debate sintetizado en 1845 por medio de las conocidas "Teses sobre Feuerbach" y "La ideología alemán" (elaborada contribuciones adensadas principalmente en los manuscritos económicos de 18571858 (conocidos como "Grundrisse" - 2011) esenciales para "El Capital". Por tanto, cualquier intento que actúe en el sentido de segmentar el conjunto de la obra de los dos autores (y el diálogo entre ellos), considerando un necesario proceso de madurez, aciertos y errores, con rupturas y continuidades, peca por impedir una explicación procesual, histórica y materialreal de la teoría social de Marx y de la ontología del ser social (en el sentido lukácsiano). Se ubica, aquí, una de las mayores contribuciones de Lukács: el rescate de la categoría marxiana de la totalidad, como complexo social repleto de mediaciones, de particularidades reconstruidas a partir de la propia dinámica de lo real, por eso materiales-ontológicas.

La ontología en Marx es impensable sin la aprehensión de su teoría social en su totalidad. Es decir, se refiere a un determinado tipo de ser, el ser social (como plantea Lukács), históricamente constituido a partir de determinadas condiciones socio-históricas. La teoría social de Marx se sustenta en tres pilares indisociables: la teoría del valor-trabajo, la dialéctica materialista y la perspectiva de la revolución del orden burgués (como referencia objetiva y posible - paralela a cualquier tipo de idealismo revolucionario o inmovilismo del sujeto histórico).

con Engels), hizo que fueran imprescindible para el "Marx maduro". Eso permitió al autor de "El capital" profundizar sus estudios y críticas a la economía política clásica (específicamente Smith y Ricardo), bien como superar los límites del socialismo utópico. 
Aunque esas tres dimensiones tengan sus particularidades, es decir, no puedan ser identificadas (igualadas) en el trato de esa teoría social, cualquier iniciativa que las fragmente compromete su explicación como componente de una totalidad social. En otras palabras, la explicación de una de ellas exige su análisis como parte de una totalidad impensable sin un tratamiento de las otras dos dimensiones. Se encuentran, aquí, las raíces de uno de los mayores equívocos cometidos contra la obra de Marx: la reducción de su teoría social a cierto tipo de economicismo-positivista y la identificación de su dialéctica con una idea de "aplicación" reducida al manejo abstracto de la tesis, antítesis y síntesis. En ese contexto, tanto aquellos que combaten a Marx y a su tradición, como también a determinados sectores del propio marxismo (ambos con objetivos diversos), lo han transformado únicamente en un "economista" o en un determinado experto comprometido con el "socialismo científico", absolutamente desnudo de dialéctica (considerada una fragilidad de juventud). En otras palabras, después de más de 150 años, segmentos no marxistas y parte de la tradición de Marx no han comprendido al autor de "O Capital". Es por eso que Lukács insiste en un regreso a Marx no para reproducir mecánicamente, a-históricamente sus contribuciones, sino para a partir de ellas, de sus bases centrales, explicar nuestra historicidad. Aquí están dadas, para Lukács, las bases para una "ontología del ser social", responsable de rescatar la esencia de la obra marxiana como reconstrucción mental de una historicidad determinada por el orden burgués a partir de la condiciones de la revolución burguesa inglesa del siglo XIX.

Por tanto, el esfuerzo teóricoanalítico presentado a continuación posee un carácter inevitable de síntesis (limitada a 20 páginas). Es, por ello, parcial, aunque intente no reproducir fragmentaciones típicas de abordajes comprometidos con teorías del conocimiento no ontológicas, fabricadas en la mente de investigadores que acaban por imponer "la cosa de la lógica" violentando "la lógica de la cosa" (Marx, 2005a, p. 39), es decir, de la propia cosa (de la realidad).

\section{Teoría social de Marx y perspectiva de totalidad: fundamentos para una ontología materialista, dialéctica e histórica}

La teoría social de Marx no puede ser explicada como un conjunto de conocimientos y recetas científicas que, correctamente aplicadas, conducen a determinado saber académico-teórico que ocupa su espacio y ofrece su contribución para el "amplio", “armónico", especializado y "plural" campo de las ciencias humanas y sociales aplicadas. No se trata, por tanto, de una prescripción científica destinada a la práctica y "a los de la práctica”, forjada en la mente genial de los estudiosos por medio de un esfuerzo teóricointelectual, mentalmente producido por los que, munidos de una acumulación de conocimientos y de buenas ideas, producen estudios académicos. Romper con la noción de aplicación de teorías y de métodos, y cuestionar la ruptura entre teoría y práctica en sus diversas expresiones teoricistas y practicistas, es camino necesario, insustituible, para capturar la riqueza de la teoría social de Marx (Lukács, 2010 y 2012, pp. 281-422).

Elmétodoen Marxcomponeunodelos pilares de su teoría social. Él es impensable sin otros dos elementos fundantes: la teoría del valor trabajo y la perspectiva de la revolución como posibilidad históricoobjetiva. Este trípode, necesariamente explicable en su unidad-diversa, es decir, unidad de los diferentes que no los identifica, sino que los particulariza en la totalidad de la vida social, es orientado por el punto de vista ontológico, por la razón que mira la vida real de seres reales, su producción y reproducción material y espiritual como seres sociales de "carne y hueso", concretamente existentes. 
No es necesario un gran esfuerzo para argumentar que el escenario actual no estimula el tratamiento de lo real a partir del punto de vista de la totalidad, para más allá de su inmediaticidad, como "concreto pensado” (Marx, 1989, p. 410), como unidad contradictoria que se compone en un proceso material-intelectual. El funcionamiento del orden burgués maduro reafirma, cotidianamente, el tratamiento inmediato, fenoménico de lo real. Ese procedimiento involucra simples acciones cotidianas en la relación directa con el consumo de mercancías objetivadas por medio del trabajo humano-abstracto (Marx, 1983)3, hacia iniciativas aparentemente más complejas, llamadas "académicas", marcadas por el "rigor técnico", orientadas por la ciencia burguesa de perfil únicamente instrumental, descriptivo y sin el menor compromiso con la necesaria mediaticidad de la vida social.

El punto de vista ontológico exige una relación orgánica con la realidad en todo proceso de producción de conocimiento. $\mathrm{Su}$ punto de partida (solo como punto de partida) es la realidad que incita, provoca, impone desafíos, indaga, apunta dudas, expresa contradicciones que, aún, solamente son desvelados con el apoyo de la razón crítica que se propone explicar la dinámica interna del mundo concreto. Lo real no se revela enteramente; carece de una dimensión racional-intelectual que mira la realidad y reconstruye sus determinaciones, sus categorías y mediaciones constitutivas (siempre relativamente). Por ello, el conocimiento orientado por la ontología del ser social, históricamente determinado, con su existencia real-concreta, reconoce un movimiento material situado más allá

\footnotetext{
3 La realización de un valor de uso por medio del cambio, proceso mediado por una única mercancía que no se compra o se vende (el dinero como equivalente general), se objetiva involucrando una relación misteriosa, fetichizada que, aparentemente y de inmediato, como producto final acabado, elimina el proceso responsable por la producción de tales mercancías (Marx, 1983, p. 70).
}

de las mentes pensantes, de la abstracción filosófica orientada por la subjetividad del ser o por un conjunto de reglas científicamente manipuladas por el rigor del investigador, una vez que persigue el movimiento de lo real, la racionalidad en ella contenida. Hay, por eso, una clara distinción entre la dimensión ontológica (contenida en la propia realidad) y la dimensión gnoseológica (de producción de conocimientos acerca de esa realidad), destacando, aquí, la diferencia entre lo real, su dinámica, y sus representaciones (no necesariamente comprometidas con la lectura crítica de la realidad). Destaca Marx (1989):

[...] a totalidade concreta, como totalidade de pensamento, como uma concreção de pensamento, é, na realidade, um produto do pensar, do conceber; não é de nenhum modo o produto do conceito que se engendra a si mesmo [...]. O todo, tal como aparece na cabeça, como um todo de pensamento, é um produto da cabeça pensante, que se apropria do mundo da única maneira em que o pode fazer, maneira que difere do modo artístico, religioso e prático-espiritual de se apropriar dele. O objeto real [reale Subjekt] permanece em pé antes e depois, em sua independência e fora da cabeça ao mesmo tempo, isto é, a cabeça não se comporta senão especulativamente, teoricamente [...]. (1989, pp. 410-411)

Utilizando las palabras de Lukács (2012, p. 303):

[...] Do ponto de vista metodológico, é preciso observar desde o início que Marx separa nitidamente dois complexos: o ser social, que existe independentemente do fato de ser mais ou menos corretamente conhecido, e o método de sua apreensão ideal mais adequada possível [...]. 
Entre tanto, esa reconstrucción no es espontanea, no brota naturalmente de esa realidad. Carece, por tanto, de la razón pensante potenciada por sujetos históricos posibles, relativos, que se apropian de ese movimiento material con el objetivo de desvelarlo. Todo ese proceso no prescinde de otras dos categorías importantes: el legado histórico y el momento histórico (la historicidad). De esta forma, estamos delante de otra relación entre sujeto y objeto, entre razón y realidad, explicada por su unidad-diversa, una producción de conocimientos que parte de demandas reales, inmediatamente puestas, y las trascienden reconstruyendo múltiples mediaciones extraídas de la propia dinámica de lo real. La teoría social de Marx y su método de estudio no se identifican con abstracciones técnico-científicas que privilegian la razón idealista que gira alrededor de ella y crea, funda o domina totalmente la realidad y su movimiento. Se contrapone, por tanto, al idealismo objetivo-dialéctico de Hegel y al idealismo subjetivo de Kant. Niega, entonces, la imposibilidad de una razón objetiva, como razón únicamente subjetiva y fenomenal kantiana, bien como la razón absoluta hegeliana (la totalidad existente en el concepto - y no en la propia realidad), el espíritu absoluto dialéctico, el idealismo objetivo, que se impone delante de la vida material, manipula su movimiento, funda su lógica sustituyendo la génesis real por la deducción lógica que establece abstractamente los parámetros materiales ${ }^{4}$.

4 Aunque Hegel reconozca la existencia de la realidad distintamente de la razón pensante y la posibilidad de conocer su lógica por medio de la dialéctica. En ese sentido avanzó sustancialmente en relación a Kant. Criticar Hegel no significa, en absoluto, no reconocer su importancia para la filosofía y para la teoría social de Marx. Destaca Lenin: "Não se pode compreender plenamente O Capital de Marx e, em particular, seu primeiro capítulo, sem estudar atentamente e sem compreender toda a Lógica de Hegel. Por conseguinte, após meio século, nenhum marxista compreendeu Marx!" (Lenin, en Lukács, 2012, p. 299).
Hay que apuntar las innumerables mistificaciones hegelianas inmersas en un "esterco de contradicciones".

[...] É necessária, porém, a máxima clareza quanto ao fato de que o verdadeiro ponto de partida éa própria realidade, que sua decomposição abstrativa conduz a categorias de espelhamento, cuja construção sintética representa um caminho para conhecer a realidade, mas não o caminho da própria realidade, embora seja óbvio que as categorias e conexões que surgem nesse processo possuem - enquanto reproduções ideais da realidade - carácter ontológico e não lógico - A ambivalência da lógica hegeliana deriva, também nesse caso, de sua fundação no idealismo objetivo, da concepção do sujeitoobjeto idêntico, que não só impede uma clara separação entre categorias e métodos ontológicos e categorias e métodos lógico-gnosiológicos, não só gera uma permanente mistura entre os dois níveis, mas também subordina continuadamente as verificações ontológicas aos pontos de vista lógicohierárquicos e, desse modo, violenta e deforma aquelas verificações. (Lukács, 2012, p. 243)

Dicho esto, es necesario resaltar que el método en la teoría social de Marx no se vincula con cualquier tipo de abstracción, aunque jamás se rinda a las diferentes formas de materialismo que se limitan a constatar lo inmediatamente posible. No se trata de establecer una media entre esas dimensiones opuestas, sino de superarlas en sus limitaciones concretas. El método en Marx no se compromete con la "cosa de la lógica” ni con la apariencia de la cosa en sí, como ella se presenta inmediatamente a los ojos del ser. La razón no crea lo real, sino que lo persigue en su movimiento, reproduciéndolo mentalmente como "lógica delacosa"(Marx, 2005a,p.39),como"concreto pensado” (Marx, 1989, p. 410). La realidad 
en sí, a su vez, no se revela naturalmente, sensiblemente, inmediatamente, pues carece de desconstrucción impensable sin la razón crítica, proyectando previamente (teleológicamente e intencionalmente) acciones posibles, reales, sobre el mundo material. Por tanto, los hombres poseen un papel activo (aunque relativo) en la construcción de la realidad, ya que ayudan a construir su propia historia, al mismo tiempo que son igualmente tejidos por ella, limitados por las condiciones materiales impuestas por determinada historicidad. No hacen historia como desean, sino como pueden hacerla, tejiéndola en un proceso altamente complejo y repleto de múltiples mediaciones y contradicciones. Es en ese proceso material-intelectual que se forman las consciencias, se hacen las luchas materiales por intereses de clases sociales reales, se establecen las ideologías (como generalizaciones parciales de lo real), se reconstruyen mediaciones y alternativas objetivas (también influenciadas por situaciones casuales, generadas por casualidad - no provocadas por los hombres), que permiten mantener o transformar la realidad orientada conscientemente por diversas perspectivas vinculadas a la existencia real de las clases en lucha.

$\mathrm{O}$ concreto é concreto, porque é a concentração de muitas determinações, isto é, unidade do diverso. Por isso, o concreto aparece no pensamento como o processo de concentração, como resultado, não como ponto de partida e, portanto, o ponto de partida também da intuição e da representação. No primeiro caminho a representação plena volatiliza-se na determinação abstrata; no segundo, as determinações abstratas conduzem à reprodução do concreto por meio do pensamento. 'Assim é que Hegel chegou à ilusão de conceber o real como resultado do pensamento que se concentra, que se aprofunda em si mesmo e se apreende a partir de si mesmo como pensamento móvel'; enquanto que o método que consiste em elevar-se do abstrato ao concreto não é senão a maneira de proceder do pensamento para se apropriar do concreto, para reproduzi-lo espiritualmente como coisa concreta [...]. (Marx, 1989, p. 410)

Ora, esa perspectiva funda otra forma de relacionarse con la realidad, establece una nueva relación entre pensamiento y realidad, entre los hombres $y$ el mundo existente, repone en otro nivel el significado de la ciencia y de la producción del conocimiento, de la teoría y de la historia, una vez que establece el punto de vista ontológico-material (de la vida real de seres reales) como referencia a la praxis social. La teoría social de Marx rechaza, así, concepciones materialistas que se conforman con lo inmediatamente sensible, sin historia, y cortan la acción práctico-política de los hombres como sujetos históricos posibles participantes de la praxis social, contempladores de la realidad. Marx destaca en las tesis sobre Feuerbach:

O principal defeito de todo o materialismo existente até agora - o de Feuerbach incluído - é que o objeto [Gegenstand], a realidade, o sensível, só é apreendido sob a forma do objeto [Objekt] ou da contemplação; mas não como atividade humana sensível, como prática, não subjetivamente. Daí decorreu que o lado ativo, em oposição ao materialismo, foi desenvolvido pelo idealismo - mas apenas de modo abstrato, pois naturalmente $\mathrm{o}$ idealismo não conhece a atividade real, sensível como tal [...].

O ponto de vista mais alto a que leva o materialismo 'contemplativo', isto é, o materialismo que não concebe o sensível como atividade prática, é a contemplação dos indivíduos singulares na 'sociedade burguesa'. $O$ 
ponto de vista do velho materialismo é a sociedade 'burguesa'; o ponto de vista do novo é a sociedade humana, ou a humanidade socializada. Os filósofos apenas 'interpretaram' o mundo de diferentes maneiras; porém, o que importa é 'transformá-lo' (Marx, 2007, p. 537 y 539).

Lukács, a su vez, recuerda (2010, p. 71): A crítica de Marx é uma crítica ontológica. Parte do fato de que o ser social, como adaptação ativa do homem ao seu ambiente, repousa primária e irrevogavelmente na práxis. Todas as características mais relevantes desse ser podem, portanto, ser compreendidas apenas a partir do exame ontológico das premissas, da essência, das consequências etc. da práxis em sua constituição verdadeira, ontológica [...].

Las observaciones tejidas por Lukács remiten a otra importante categoría contenida en la teoría social de Marx ${ }^{5}$ la categoría de la totalidad. La realidad es rica en determinaciones, está saturada de múltiples mediaciones que explican la dinámica de complejos sociales materialmente existentes (trabajo, clase social, conciencia, ideología, pauperismo, entre otros). Ella, siempre se expresa inmediatamente en la esfera de la vida cotidiana, como un complejo aparentemente simple, que elimina - en su forma sensible inmediata - el proceso que la explica y la constituye. Lukács denomina eso de singularidad de la vida social, no suprimible como tal, típica de las relaciones inicialmente puestas, la forma de aparición inicial de las relaciones complejas. Eso puede ser sintéticamente explicado por

5 Las categorías no nos títulos conceptuales creados y manejados por la razón "científica" que impone a la realidad su lógica. Las categorías son "formas de vida, determinaciones de existencia”, es decir, existen en la propia realidad. medio de un ejemplo relativamente simple. Inmediatamente la mercancía zapato, al ser expuesta en una tienda, elimina todo proceso necesario para su producción. Ese proceso está contenido en los zapatos como trabajo socialmente acumulado que, debidamente analizado (más allá de su dimensióninmediata), explica nosolamente la mercancía zapato, sino todo proceso que lo constituyó por medio de la producción del valor creado por el trabajo humano. Ora, ¡se trata de relaciones socialmente constituidas! El secreto de ese contexto, su fetiche, está en eliminar aparentemente su génesis procesual descartando, así, toda la clave explicativa necesaria para apañar la vida social como totalidad social (un rasgo objetivo, real). Al hacer eso, no solamente fetichiza la mercancía, sino las relaciones sociales como un todo, tomando la parte del proceso como totalidad, la apariencia como esencia, el inmediato como mediato.

El "punto de partida" reside exactamente en ese nivel: la singularidad es esencial para la reconstrucción de lo real (parte de la totalidad social, no suprimible como tal), pero insuficiente por presentarse siempre inmediatamente. Esa desconstrucción operada con el auxilio de la razón dialéctica-material y orientada ontológicamente indica que no se trata solamente de relaciones inmediatamente puestas, sino de relaciones universales, socialmente explicadas, que remiten al funcionamiento de un orden social dado, su metabolismo, es decir, la forma como los hombres se organizan para producir y reproducir la vida social. Esa universalidad, para que no se pierda en generalizaciones y abstracciones, solamente puede serapañada en sus particularidades, o sea, los complejos sociales universales no se objetivan igualmente en todas las realidades, aunque compongan una universalidad, sean parte de una lógica material que no se encierra y no se explica puntualmente, localmente y solamente por dinámicas individuales.

La particularidad es el reino de las mediaciones, de las conexiones explicativas 
realmente existentes y mentalmente reconstruidas por la razón ontológicomaterial. Esen esa tramadinámica destacada didácticamente, solo didácticamente, entre lo singular, lo universal y lo particular, que se inscribe la categoría de la totalidad que constituye la realidad social y que es componente del método en la teoría social de Marx. El punto de vista de la totalidad no se confunde con un todo articulado, sistémicamente interconectado, reducido a la comunicación intensa de la partes, mucho menos se resume a una visión genética, estéril, que disuelve las partes en el todo. La noción de totalidad resalta la unidad de dimensiones diferentes que son impensables, inexplicables, sin la íntima conexión entre lo inmediatamente aparente y el proceso genético que lo explica. Lo singular, lo inmediatamente establecido, contiene el todo en su riqueza (la universalidad del proceso), con sus múltiples particularidades $y$ mediaciones, aunque no lo revele como tal inmediatamente. Los individuos, seres sociales humano-genéricos, son productos sociales de una construcción históricahumana que traen en su constitución el legado humano-genérico, la construcción histórico-humana. Esa es la trama que compone la totalidad como categoría material-intelectual indivisible que une, sin identificar, la singularidad, la universalidad y la particularidad. Al contrario de Hegel, en Marx lo contradictorio no es una categoría puramente lógica, una transposición de una fase a otra como parte de una razón idealista-objetiva que se impone abstractamente sobre la realidad y su movimiento, sino la fuerza motriz de todo proceso material, objetivo, parte constituyente de luchas reales establecidas entre posiciones sociales distintas, motor para cambios prácticos. La contradicción "se revela como princípio do ser precisamente porque é possível apreendê-la na realidade também enquanto base de tais processos" (Lukács, 2012, p. 291).

Aunque el punto de partida sea siempre ontológico, la razón tiene el papel fundamental de poner en movimiento esa reconstrucción, forjar lo real en su dureza, en su inmediaticidad innata, sin lo cual es imposible desvelarlo. La razón por tanto, no puede quedarse dando vueltas en el cerebro "ilustre" del filósofo y de los académicos munidos de la "barita mágica" del conocimiento, ella no funda lo real, no posee la potencia para crear la realidad. Lo que se defiende, aquí, no es la eliminación de la razón o su reducción, su desvaloración, sino la unidad-diversa entre pensar y hacer, entre razón crítica y lo inmediatamente puesto. La teoría, entonces, posee el papel dealumbrarel proceso, auxiliar el proceso de conocimiento sobre la realidad. El método no se reduce a esquemas explicativos de un conjunto de técnicas, sino que se objetiva como un camino que orienta las bases para que la razón conozca el real y su movimiento y produzca teoría. Todo ese proceso, ontológico, está metido en la trama histórica, inmerso en la historicidad dada que ofrece el piso, la base material, por donde las individualidades toman decisiones, elaboran alternativas, ejercen su papel como sujeto histórico posible, ciertamente limitado, relativamente activo, marcado por el orden del capital tejido por luchas sociales de clase. Se objetiva, así, otra relación entre teoría, método e historia, muy distante de esquemas lógico-formales, abstractos, que imponen a lo real, como ya dicho, una dinámica que esconde en vez de revelar, camufla en vez de desvelar. En resumen,

[...] Marx, parte, ao contrário, da totalidade do ser na investigação das próprias conexões, e busca apreendê-las em todas as suas intrincadas e múltiplas relações, no grau máximo de aproximação possível. A totalidade não é, nesse caso, um fato formal do pensamento, mas constitui a reprodução ideal do realmente existente; as categorias não são elementos de uma arquitetura hierárquica e sistemática, mas, ao 
contrário, são na realidade "formas de ser, determinações de existência", elementos estruturais de complexos relativamente totais, reais, dinâmicos, cujas inter-relações dinâmicas dão lugar a complexos cada vez mais abrangentes, em sentido tanto extensivo quanto intensivo. [...] enquanto crítica ontológica de todos os tipos de ser, a filosofia continua sendo, todavia, sem pretensão de dominar e submeter os fenômenos e suas conexões, o princípio condutor dessa nova cientificidade [...]. (Lukács, 2012, p. 297)

Las consecuencias de esto son profundas y certeras: la teoría no es construcción, sino reconstrucción, persecución del movimiento de lo real, expresión teórica de ese movimiento (siempre relativa), comprometida en desvelar lo inmediatamente establecido, revelar sus particularidades en la totalidad de la vida social y comprometerse con la orientación de acciones prácticas (como orientación general y no como “aplicación"). Todo eso es tejido en la y a partir de la historia real de seres sociales reales, empeñados en alterar (dentro de sus posibilidades) el curso de la historia. No hay, aquí, ningún compromiso con una perspectiva que reduzca la teoría a una aplicación inmediata, utilitarista, tampoco ningún vínculo con una noción de ciencia linealmente histórica, que se dice "neutra" y descriptiva de lo real. En ese nivel no es posible pensar en la teoría separada del método y de la historia concreta de los hombres y vice-versa. Más aún, la teoría no es un conglomerado de conocimientos elaborados abstractamente por el saber científico, metódicamente organizado, pero sí una forma específica de conocimiento, una reproducción ideal del movimiento del objeto elaborada por el sujeto de la investigación. El método no es un conjunto de procedimientos formales capaces de decodificar el objeto de estudio (correctamente "aplicados” y "manejados”), pero sí un camino que auxilia en la reconstrucción de la "lógica de la cosa", del "objeto de estudio". Mucho menos la historia se limita a una sucesión lineal y evolutiva de hechos y acontecimientos desconectados o sistémicamente relacionados, aunque no se pueda decir, en absoluto, que los complejos sociales se conectan naturalmente, unos con los otros. Hay, entre ellos, unidad, pero no identidad, bien como una dosis de casualidad que tempera la lucha de clases. Por tanto, no está demás repetir, teoría no es construcción, sino reconstrucción del movimiento de lo real, expresión teórica de su movimiento (siempre relativa), revelando tensiones contenidas en la dinámica de la realidad, relacionadas con la producción y reproducción del ser, su desarrollo, comprometida en desvelar genéticamente lo real, su dinámica interna, sus particularidades en la totalidad de la vida social, repleta y rica en múltiples mediaciones, es decir, conexiones explicativas extraídas de la propia realidad. Es por ello que Lukács insiste en decir que la ortodoxia marxiana reside, únicamente, en su método de análisis.

O marxismo ortodoxo não significa, pois, adesão acrítica aos resultados da pesquisa de Marx, nem "fé" numa ou noutra tese marxiana ou a exegese de um texto "sagrado". A ortodoxia, em matéria de marxismo, referese, ao contrário e exclusivamente, ao método [...]. (Lukács, 1981, p. 6o)

Pero, eso aún no es suficiente para explicar la densidad de la teoría social de Marx, como ontología del ser social en términos lukácsianos. La apuesta está en destacar de este referente su método (como si eso fuera posible), aunque él sea el único rasgo ortodoxo en la obra marxiana conforme indicó Lukács. El punto de vista de la totalidad exige que el método sea apropiado con base en otros dos aspectos inseparables (como se ha insistido en la 
introducción de este texto): la teoría del valor-trabajo y la perspectiva de la ruptura con el orden burgués en curso (la revolución como posibilidad histórica concreta). Sin eso la teoría social de Marx se pierde por completo. Cabe destacar, sumariamente, la necesidad de considerar esas dos dimensiones sin las cuales la economía política burguesa no podría ser desvelada y radicalmente cuestionada a partir de sus contradicciones internas, ontológicamente dadas e insuperables dentro de las fronteras del capital, de su sociedad (el capitalismo) y de sus características afinadas con la propiedad privadadela producción social.Es importante reconstruir permanentemente esa tradición teórica saturándola con las ricas determinaciones repuestas a lo largo de los últimos 150 años, expresadas en el movimiento histórico marcado por un proceso de lucha de clases en tiempos de capitalismo maduro y sus particularidades objetivadas en las diferentes regiones del globo. Solamente en ese nivel es posible perseguir el movimiento de lo real, siempre relativamente, jamás exactamente. Lukács destaca la importancia de explicar las sociedades y sus individuos teniendo por base los procesos históricos y los complejos sociales que los constituyen, considerando el modo como se desarrollan, se producen y reproducen, es decir, se organizan económicamente. Eso no significa recaer en el economicismo que somete mecánicamente toda superestructura ideológica a la base económica. Se ubica, aquí, por diferentes caminos adoptados por diferentes tendencias, uno de los mayores equívocos cometidos contra Marx y su teoría social: a) la reducción de ella a una economía estricta, comouna infraestructura mecánicamente determinante (no como momento predominante - Lukács, 2012 e 2013) y la revolución como un desdoblamiento directo de cierto tipo de economía centralizada y organizada por el estado, generalizadas mundialmente como paradigma (de base stalinista), ambas dimensiones estanques, separadas por espacios bien definidos y articuladas por un tipo de positivismo adaptado, ajustado, a esas condiciones ${ }^{6}$; b) en ese mismo sentido, aunque con teleología opuesta, las orientaciones liberales/burguesas comprometidas con la reducción de Marx y de su teoría social (particularmente de la teoría valor-trabajo) a la economía estricta, especializada, "económica” (como un "Marx puramente economista"), por supuesto despida de dialéctica y de cualquier especie de orientación revolucionaria; c) una tendencia más reciente que, al revés de la dos anteriores, destaca y saca el método en Marx del conjunto de su obra, adoptándolo como "aplicación" para "comprender" la realidad, como parte de una "teoría del conocimiento". Todas ellas se encuentran en un punto fundamental: la absoluta destruición de la categoría de la totalidad promoviendo una parcialización grosera que destruye la esencia histórica, dialéctica y revolucionaria de la teoría social de Marx. [...] uma ontologia do ser social deve, portanto, se não quiser falsear os nexos ontológicos, tentar apreender exatamente seus traços específicos em seu originário ser-propriamenteassim. E para o ser social é profunda e decisivamente característico que todos os processos dinâmicos dos complexos da práxis humana, só nele constituídos e só nele possíveis, sejam quanto à sua gênese fundados no respectivo modo de desenvolvimento da sociedade, em sua economia, e que sejam por ela determinados até as suas características específicas; em sua dinâmica imediata, ao contrário, podem reclamar para si uma muito ampla vida própria, um desdobramento dinâmico próprio, tanto em termos formais como em

6 Lo que no significa desconocer la importancia histórica de la ex-Unión Soviética, sea como alternativa al capitalismo occidental por más de 70 años o como oposición al nazi-fascismo (decisivo para su derrumbe). 
termos de conteúdo [...]. Um dos motivos principais da vulgarização do marxismo, que tanto colaborou para que ele perdesse sua influência como teoria universal do desenvolvimento da humanidade, foi exatamente a concepção mecanicista de toda ideologia como mero 'produto naturalmente necessário' das respectivas relações econômicas. (Lukács, 2010, pp. 100-113)

El vínculo estructural del método en Marx con la teoría del valor-trabajo y la perspectiva de la revolución (siempre como posibilidad materialmente puesta a partir de condiciones históricas bien definidas) posee el exacto sentido de explicar la producción y la reproducción del ser, teniendo el trabajo como categoría fundante de su sociabilidad, como praxis primera, como categoría que permite a los hombres disminuyeran paulatinamente las barreras naturales, humanizaran la naturaleza al mismo tiempo que son transformados por ese proceso y por su relación con los otros hombres. Ese cambio ocurre por medio de la propia fuerza humana, sin eliminar su base natural, teniendo el trabajo (útil, concreto) como punto central para la recreación del ser y de sus relaciones humano-naturales. Esa tendencia puede ser constatada mucho antes de la era del capital, desde el momento, por ejemplo, en que los hombres pasaran a dominar conscientemente, intencionalmente, diferentes técnicas, como trabajo creativo, útil, siempre teniendo como punto de partida su existencia concreta. Por eso, "a essência do trabalho humano consiste no fato de que, em primeiro lugar, ele nasce em meio à luta pela existência e, em segundo lugar, todos os seus estágios são produto de sua autoatividade" (Lukács, 2013, p. 43)7.

\footnotetext{
7 Es importante destacar sumariamente que aunque la realidad sea el punto de partida del conocimiento (en eso la vida cotidiana adonde los hombres ponen en movimiento sus capacidades por entero, pero no enteramente/plenamente - como insiste Lukács), existen diferencias entre el arte y la ciencia como
}

El dominio de la técnica de producción del fuego y del uso de la agricultura, por ejemplo, expresaron saltos ontológicos inmensos para la especie humana, cambiando radicalmente la relación de los hombres con la naturaleza, consigo propio y con las otras especies. El trabajo, como categoría fundante para la relación orgánica hombre y naturaleza, ciertamente acometida por momentos de incertidumbre, fue absolutamente central para la sobrevivencia y para la evolución de la especie humana y continúa siendo fundamental para la diminución de las barreras naturales en los días de hoy ( $\sin$ eliminarlas por completo) $)^{8}$. La teoría social de Marx, entendida como ontología del ser social, no separa la naturaleza y el ser social, aunque nos los identifique. Es exactamente el trabajo que permite una relación orgánica hombre-naturaleza, como previa ideación consciente y anteriormente proyectada-planeada en el cerebro humano (como finalidad-causalidad), como trabajo universal que permite los sucesivos saltos ontológicos que reducen las barreras naturales sin jamás eliminarlas totalmente. Tiene, por tanto, siempre, como punto de partida, sus propias condiciones deexistencia (eso es importante). Por tanto, los hombres constituyen la naturaleza, forman parte de ella, pero al mismo tiempo superan su condición únicamente natural por medio del trabajo concreto. Eso los diferencia de los otros animales cuyas actividades están estructuralmente vinculadas a su existencia inmediata, biológica, natural. En las palabras de Marx (1983, p. 150, 153):

\footnotetext{
formas superiores de reflejos que trascienden la cotidianeidad. Mientras el primer tiene un carácter antropomorfizador (mezclando subjetividad y objetividad en el proceso de creación), la segunda valora un procedimiento desantropomorfizador, es decir, una tendencia de reproducir lo más correctamente posible la lógica de la propia realidad (Lukács, 1978).

8 Se debe destacar el hecho de que ese proceso, comandado por el capital, ha llevado la propia naturaleza a graves niveles de agotamiento. Mészáros (2002, pp. 603-980) destaca ese tema al tratar de la crisis estructural del sistema del capital.
} 
Uma aranha executa operações semelhantes às do tecelão $\mathrm{e} a$ abelha envergonha mais de um arquiteto humano com a construção dos favos de suas colmeias. Mas o que distingue, de antemão, o pior arquiteto da melhor abelha é que ele construiu o favo em sua cabeça, antes de construí-lo em cera. No fim do processo de trabalho obtem-se um resultado que já no início deste existiu na imaginação do trabalhador, e portanto idealmente. Ele não apenas efetua uma transformação da forma da matéria natural; realiza, ao mesmo tempo, na matéria natural seu objetivo, que ele sabe que determina, como lei, a espécie e o modo de sua atividade e ao qual tem de subordinar sua vontade. [...] $\mathrm{O}$ processo de trabalho, como apresentamos em seus elementos simples e abstratos, é atividade orientada a um fim para produzir valores de uso, apropriação do natural para satisfazer a necessidades humanas, condição universal do metabolismo entre o homem e a Natureza, condição natural eterna da vida humana e, portanto, independente de qualquer forma dessa vida, sendo antes igualmente comum a todas as suas formas sociais [...].

El trabajo abstracto-alienado/ extrañado, la forma como la categoría trabajo se ha objetivado a partir del mando del capital, vive en permanente crisis y es el responsable por la deshumanización humana (Marx, 1983, 1984, 2004). En la sociedad del capital el trabajo deja de ser, en gran medida, una realización humana, en el sentido ontológico, concreto, transformándose en trabajo cosificado, subyugado al capital, configurándose como una forma histórica de trabajo. Ese tipo de trabajo separa el hombre (fuerza de trabajo), los instrumentos de producción (máquinas, herramientas, etc...) yel productodel trabajo (como mercancía). Al hacer eso, transforma la fuerza de trabajo en una mercancía específica, cosifica las relaciones humanas por medio de un fetiche mercadológico, instituye la propiedad privada fundada en la privatización de la producción social, alienando/extrañando los hombres y los productos del trabajo de ellos. Por tanto, las potencialidades emancipadoras contenidas en la categoría trabajo son, en el reino del capital, subsumidas - aunque no sean eliminadas - por una forma de trabajo que somete el acto de la creación como trabajo concreto a la valorización del capital (por supuesto desde el inicio del proceso), por medio del trabajo alienadoextrañado, abstracto, asalariado, destinado a la pura sobrevivencia, a la satisfacción de carencias humanas mínimas (Marx, 2004, pp. 79-90). Mientras el trabajo abstracto se vincula a la producción ampliada del capital (pudiendo dejar de existir con la superación del él y del capitalismo), el trabajo concreto, por ser una categoría mediadora de la sociedad humana, debe ser liberado como componente no suprimible de la emancipación humana conquistada socialmente y expresada individualmente en los hombres, con sus "fuerzas propias" como "fuerzas sociales" (Marx, 2009, p. 71). Enlosmanuscritosde1844losestudios marxianos ya apuntaban claramente esa sumisión del trabajo humano útil al capital, aunque esa tendencia se objetivara más adelante en "El capital".

O trabalhador se torna tanto mais pobre quanto mais riqueza produz [...] O trabalhador se torna uma mercadoria tão mais barata quanto maior mercadorias cria. Com a valorização do mundo das coisas (Sachenwelt) aumenta em proporção direta a desvalorização do mundo dos homens (Menschenwelt). O trabalho não produz somente mercadorias; ele produz a si mesmo e ao trabalhador 
como uma mercadoria ${ }^{9}$, e isto na medida em que produz, de fato, mercadorias em geral. [...] O trabalho produz maravilhas para os ricos, mas produz privação para o trabalhador. Produz palácios, mas cavernas para o trabalhador. Produz beleza, mas deformação para o trabalhador. Substitui o trabalho por máquinas, mas lançauma partedos trabalhadores de volta ao trabalho bárbaro e faz da outra parte máquinas. Produz espírito, mas produz imbecilidade, cretinismo para o trabalhador [...]. (Marx, 2004, p. 8o, 82)

Lacontinuidadylaprofundizacióndelos estudios de Marx en el campo de la economía política (entendida como producción y reproducción de la existencia humana a partir de condiciones históricas dadas), siempre orientado por la perspectiva de la totalidad, continúan en la "Miseria de la filosofía" (1987), son densamente profundizados en los "Grundrisse" (2011) y en los manuscritos de 1861-1863 (2010), materializándose más densamente en "El capital".

O trabalhador trabalha sob o controle do capitalista a quem pertence seu trabalho. O capitalista cuida de que o trabalho se realize em ordem e os meios de produção sejam empregados conforme seus fins, portanto, que não seja desperdiçada matéria-prima e que o instrumento de trabalho seja preservado, isto é, só seja destruído na medida em que seu uso no trabalho o exija [...]. A partir do momento em que ele entrou na oficina do capitalista, o valor de uso de sua força de trabalho, portanto, sua utilização, o trabalho, pertence ao capitalista. O capitalista, mediante a compra da força de trabalho, incorporou o próprio trabalho, como fermento vivo, aos elementos mortos

9 Grifos de Marx. constitutivos do produto, que lhe pertencem igualmente. Do seu ponto de vista, o processo de trabalho é apenas o consumo da mercadoria, força de trabalho por ele comprada, que só pode, no entanto, consumir ao acrescentar-lhe meios de produção. O processo de trabalho é um processo entre coisas que o capitalista comprou, entre coisas que lhe pertencem. O produto desse processo lhe pertence de modo inteiramente igual ao produto do processo de fermentação em sua adega. (Marx, 1983, p. 154)

Es por eso que la forma como la categoría trabajo se ha objetivado y particularizado en el capitalismo ${ }^{10}$, subsumiendo su dimensión útil-concreta, carece de crítica permanente, radical, material, capaz de liberarlo como fuerza humanizadora de los seres sociales, libertad fundamental para estimular el desarrollo de su potencia humano-genérica, realizarse en su diversidad y poner su particularidad al servicio del colectivo. No se trata, aquí, de una crítica abstracta, centrada en el puro deseo-intensión, sino de una crítica objetiva, real, vinculada a aspectos que sustentan objetivamente la reproducción ampliada del capital y su sociedad. Es en ese sentido que la crítica radical de Marx en la teoría valor-trabajo, sobre todo por medio de la explicación de los mecanismos de extracción material de la plus-valía, del trabajo como fuente original del valor en las diferentes fases del capitalismo, adquiere materialidad efectiva como posibilidad de ruptura revolucionaria (no como destino fatal), teniendo en cuenta la no sustentabilidad objetiva de una sociedad que para reproducirse repone, continuadamente, contradicciones insolubles sobre sus fronteras. Esa tendencia se profundizó y se objetivó

10 La sociedad que permite la reproducción ampliada del capital. 
gradualmente en la obra marxiana desde sus "estudios de juventud", claramente expuestos (y coherente con el conjunto de su teoría social) en "La cuestión judía" (2009) y en "Crítica a la filosofía de Hegel introducción” (2005b).

Toda a emancipação política é a redução do homem, por um lado, a membro da sociedade civil, a indivíduo egoísta independente; por outro, a cidadão, a pessoa moral. Só quando o homem individual retoma em si o cidadão abstrato e, como homem individual - na sua vida empírica, no seu trabalho individual, nas suas relações individuais -, se tornou ser genérico; só quando o homem reconheceu e organizou as suas forces propres (forças próprias) como forças sociais e, portanto, não separa mais de si a força social na figura da força política ${ }^{11}$ - [é] só então [que] está consumada a emancipação humana. (Marx, 2009, p. 71)

Quando o proletariado anuncia a dissolução da ordem social existente apenas declara o mistério da sua própria existência, uma vez que é a efetiva dissolução desta ordem. Quando o proletariado exige a negação da propriedade privada, apenas estabelece como princípio da sociedade o que a sociedade já elevara a princípio do proletariado e o que este já involuntariamente encarna enquanto resultado negativo da sociedade [...]. Assim como a filosofia encontra as armas materiais no proletariado, assim o proletariado tem as suas armas intelectuais na filosofia. (Marx, 2005b, p. 156)

Lukács (2012, p. 415) destaca la absoluta coherencia entre la teoría social de Marx como ontología del ser social y la perspectiva de la revolución como

11 Grifos de Marx. componente de esa ontología. Es decisivo destacar que el socialismo (como primera etapa del comunismo), destaca Lukács, se presenta como desdoblamiento normal y necesario de la "dialéctica del ser social", de una "auto explicación" de la economía real, sus presupuestos como resultado de la lucha de clases (siempre como posibilidad histórica objetiva). No se impone, aquí, una revolución como un acto utópico, abnegado, idealista, desconectado de la realidad. Al revés, el suceso de la revolución depende de un conjunto de elementos que articulen el desarrollo de las fuerzas productivas, la lucha de clases potenciada por sujetos históricos en una historicidad dada, la construcción de alternativas factibles, reales, siempre transitorias, posibles, seguramente imperfectas, incluso mediado por casualidades históricas, pero claramente e intencionalmente perseguidas. Más que eso, la revolución no se impondrá localmente, aisladamente, sino mundialmente, sobre todo en los espacios en los que la sociedad del capital se desarrolló más plenamente. Esto no significa descartar procesos de resistencia que brotan en regiones del globo marcadas por el capitalismo dependiente, sino afirmar que esos países no lograrán un suceso revolucionario aisladamente, a partir de ellos mismos o de un bloque de países. El colapso del capital debe contener características mundiales y estructurales. Destacan Marx y Engels en el "Manifiesto del partido comunista":

As proposições teóricas dos comunistas não se baseiam, de modo nenhum, em ideias ou em princípios inventados ou descobertos por este ou aquele reformador do mundo. São apenas expressões gerais de relações efetivas de uma luta de classes que existe, de um movimento histórico que se processa diante de nossos olhos. [...] a moderna propriedade privada burguesa é a expressão última e mais acabada da produção e da apropriação baseada em antagonismos de 
classe, na exploração de umas pelas outras. Neste sentido, os comunistas podem condensar a sua teoria numa expressão única: supressão da propriedade privada [...]. (Marx, Engels, 1998, p. 21)

Es necesario decir, entonces, que el socialismo y el comunismo no representan "el fin de la historia", y que la economía (como producción y reproducción del ser social) continuará siendo importante para la satisfacción de necesidades humanas, para la vida humana (como base ontológica permanente). La diferencia fundamental entre capitalismo y socialismo está en que el primero crea, espontáneamente, una producción social (aunque ella no se imponga tranquilamente), mientras que el segundo transforma esa espontaneidad en regulación consciente (Lukács, 2012, p. 416). Seguramente, aún aquí, el estado tendría una función importante en la regulación social, como "dictadura revolucionaria del proletariado” (Marx, 2012, p. 440) ${ }^{12}$. La polémica palabra "dictadura", ampliamente explorada por la derecha liberal como "antidemocrática” (seguramente no democrático-burguesa), o reducida a una imposición de la burocracia partidaria como un exclusivo "asalto al poder" (inspirado en la vanguardia stalinista), debe ser entendida

12 Por supuesto que la afirmación marxiana sobre el protagonismo del proletariado se sustenta en las condiciones objetivas de la segunda mitad del siglo XIX. Nuestra aprehensión es que la participación del proletariado urbano en procesos revolucionarios continúa actual, aunque sea necesario destacar, hoy, una brutal reducción del proletariado fabril (con fuerte disminución del trabajo vivo - típico del padrón de acumulación toyotista), bien como una profunda diversificación ontológica de la clase trabajadora que vive de la venta de su fuerza laboral. Eso, seguramente, insiere otros datos ontológicos que no pueden ser subestimados en el debate sobre las posibilidades revolucionarias y cuáles son sus protagonistas en el inicio del siglo XXI. Todavía, todo eso no descarta la categoría revolución como posibilidad real, tampoco la importancia de la lucha de clases y el papel de la heterogénea clase trabajadora en la fase monopólico-financiera, de inspiración toyotista, del capital. como imposición de intereses hegemónicos de clase en una fase de transformación revolucionaria, una transición socialista, de la educación y construcción de un nuevo hombre, en sentido amplio, con valores centrados en la igualdad social que no es sinónimo de identidad social, sino de igualdad en la diversidad, igualdad de las diferencias o, para Marx (2012, p. 432), “[...] De cada qual , segundo sua capacidade; a cada qual, segundo suas necessidades. [...]". No hay, aquí ningún tipo de ilusión. Todos los procesos revolucionarios pasaron por transiciones tensas en los que los grupos hegemónicos objetivamente se impusieron delante de los intereses decadentes de las viejas sociedades. Así se impuso, por ejemplo, la burguesía como clase hegemónica al final del siglo XVIII. La transición socialista y la "dictadura del proletariado" se impondrían no solamente como un asalto al poder, pero se objetivarían seguramente con acciones políticas de hombres concretos tensionando y potenciando posibilidades objetivas, reales, contenidas en las contradicciones internas del propio orden burgués, desarrollando proyectos alternativos a esa sociedad orientados por la igualdad social (en ese sentido, sí, democráticos). Por tanto, para Marx, el socialismo significa la continuidad de la historia, el "fin de la pre-historia de la humanidad", es decir, la historia continua a partir de novas bases sociales centrada en un controle consciente de la producción social, como un movimiento material-objetivo marcado por rupturas con continuidades, unidad del diverso, reposición de nuevas contradicciones. Destaca Marx en el libro III de "O Capital":

Nesse terreno, a liberdade só pode consistir em que o homem social, os produtores associados, regulem racionalmente esse seu metabolismo com a natureza, trazendo-o para seu controle comunitário, em vez de serem dominados por ele como se fora uma força cega; que o façam com o mínimo emprego de forças e sob as condições 
mais dignas e adequadas à sua natureza humana. (Marx, en Lukács, 2012, p. 416)

Como todo en Marx (en su teoría social) no existen recetas, aunque existan tendencias posibles tejidas en la vida real de seres sociales en lucha. Apuntar posibilidades no significa, en absoluto, realizarlas. La solución, en ese sentido, está en la praxis social, en un pensar-hacer concreto, histórico, historiado, orientado por el punto de vista de la totalidad y contaminado por una explícita no neutralidad a favor de los que viven de la venta de la fuerza laboral (aunque ellos mismos, en tiempos de hegemonía del capital, nos reproduzcan, conscientemente, la consciencia de su clase social).

\section{Observaciones finales no conclusivas}

El tratamiento de la teoría social de Marx en su totalidad es una exigencia para la ontología del ser social en el sentido lukácsiano. Su ortodoxia está, únicamente, en el método (que nos permite reconstruir, histórica y concretamente, el movimiento contradictorio de la realidad). Eso, todavía, no es nada. El desafío se impone como praxis social, es decir, en pensar, hacer y cambiar el mundo materialmente a partir de las condiciones efectivamente dadas. Cualquier pérdida de esa referencia, de esa base, significará una recaída idealista y, por supuesto, una destrucción de la razón ontológica. La pertinencia y la actualidad de la teoría social de Marx para el análisis del actual momento histórico no se sustentan en un protocolo de intenciones. Los mismos mecanismos que reponen las condiciones para la manutención ampliada del capital (hoy en su fase madura como capitalismo monopolista, financiero, orientado por un padrón de acumulación toyotista y con rasgos dependientes en el caso de Latinoamérica), reponen los propios mecanismos para su superación, reafirmando la desigualdad social estructural y los innumerables dilemas indisolubles contenidos en esa sociedad. Por tanto, reafirman las posibilidades materiales para su superación contando con las protestas del proletariado clásico y del conjunto de trabajadores desapropiados que viven, diversamente, hoy, de la venta de su fuerza laboral. La revolución no es una abstracción sino una posibilidad histórica real cuya basesesustenta en el propiocapital, que pone y repone, históricamente, las múltiples consecuencias de la apropiación privada de la producción y reproducción social explicada por la "ley general de la acumulación capitalista” (Marx, 1984, p. 187). Seguramente las particularidades actuales y sus diversas mediaciones no son las mismas si son comparadas con el tiempo histórico de Marx (o del último Lukács), pero los presupuestos fundantes reveladosy tratados por esos autores no son solamente pertinentes; más aún, son absolutamente necesarios para que actuemos contra la barbarie anunciada y ya sentida en las diferentes dimensiones de la vida social. De esta forma, la sociedad del capital, sus propias contradicciones como orden social, la lucha de clases en ella implícita, ofrecen los elementos objetivos para su superación material. El método en Marx, como parte constituyente de su teoría social, nos ofrece una base metodológica sólida para actualizar coherentemente su teoría social, sin recaídas idealistas de cualquier especie o reformismos conservadores travestidos de "democráticos". Ese choque radicalmente marxiano y seguramente anti dogmático es esencial para la resistencia genuinamente de izquierda (en su diversidad) y para el propio marxismo, como crítica y autocrítica. Nos resta reproducir las palabras de Lenin sobre el equívoco de adoptar recetas listas (Lukács, 2012, p. 422):

Nem sequer a Marx veio à mente escrever uma só palavra sobre essa questão se ele morreu sem deixar nenhuma citação precisa ou indicações irrefutáveis. Por isso, devemos nos virar por nós mesmos. 


\section{Referencias Bibliográficas}

Lukács, G. (1978). Introdução a uma estética marxista. Trad. Carlos Nelson Coutinho. Rio de Janeiro: Civilização Brasileira.

Lukács, G. (1981). Lukács. In J. P. Netto (Ed.), Introdução e antologia. São Paulo: Ática. (Grandes cientistas sociais).

Lukács, G. (2010). Prolegômenos para uma ontologia do ser social. Tradução de Carlos Nelson Coutinho. São Paulo: Boitempo Editorial.

Lukács, G. (2012). Para uma ontologia do ser social I. São Paulo: Boitempo Editorial.

Lukács, G. (2013). Para uma ontologia do Ser Social II. São Paulo: Boitempo Editorial.

Marx, K. (1983). O capital: crítica da economia política. São Paulo: Abril Cultural.

Marx, K. (1984). O capital - crítica da economia política. São Paulo: Abril Cultural, 1984.

Marx, K. (1985a). Capítulo Inédito de O Capital: resultados do processo de produção imediata. São Paulo: Editora Moraes.

Marx, K. (1985b). O capital: crítica da economia política. São Paulo: Abril Cultural.
Marx, K. (1987). Miseria de la filosofia. Respuestas a la Filosofía de la Miseria de Proudhon. México: Siglo XXI Ediciones.

Marx, K. (1989). O método da economia política. In F. Fernandes, (Ed.), Marx e Engels: história. $3^{\text {a }}$ ed. São Paulo: Ática. (Textos originais de Marx e Engels).

Marx, K. (2004). Manuscritos econômico filosóficos. São Paulo: Boitempo Editorial.

Marx, K. (2005a). Critica da filosofia do direito de Hegel. São Paulo: Boitempo.

Marx, K. (2005b). Crítica da filosofia do direito de Hegel. Introdução. In: K. Marx. Critica da filosofia do direito de Hegel (pp. 145-156). São Paulo: Boitempo.

Marx, K. (2009). Para a questão judaica. São Paulo: Expressão Popular.

Marx, K. (2011). Grundrisse. Manuscritos económicos de 1857-1858. São Paulo: Boitempo Editorial.

Marx, K. \& Engels, F. (1998). O manifesto do partido comunista. Prólogo de José Paulo Netto. São Paulo: Cortez.

Mészáros, I. (2002). Para além do capital. São Paulo: Boitempo Editorial. 